\title{
Teratogenicity and volatile composition evaluation of soymilk fermented with a Deinococcus member
}

\author{
I-Chen Li ${ }^{1}$, Wan-Ping Chen ${ }^{1}$, Yi-Chin Lin ${ }^{1}$, Charng-Cherng Chyau ${ }^{2 *}$ and Chin-Chu Chen ${ }^{1,3,4,5^{*}}$
}

*Correspondence: ccchyau@sunrise.hk.edu.tw (and) gkbioeng@grapeking.com.tw

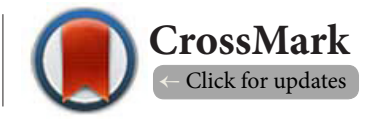

'Grape King Bio Ltd, No. 60, Sec. 3, Longgang Rd., Zhongli Dist., Taoyuan City, Taiwan.

${ }^{2}$ Research Institute of Biotechnology, Hungkuang University, No. 1018, Section 6, Taiwan Blvd, Shalu District, Taichung City, Taiwan.

3Institute of Food Science and Technology, National Taiwan University, Taipei City, Taiwan.

${ }^{4}$ Department of Food Science, Nutrition, and Nutraceutical Biotechnology, Shin Chien University, Taipei City, Taiwan.

${ }^{5}$ Department of Applied Science, National Hsin-Chu University of Education, Hsinchu City, Taiwan.

\begin{abstract}
The possibility of producing functional ingredients based on soymilk, fermented with a new identified strain Deinococcus sp. GKB-Aid 1995, was examined. Firstly, a prenatal developmental toxicity test in Sprague-Dawley rats was conducted to assess any potential human health risk. Next, owing to the unique odor that is significantly different from traditional fermented soymilk products, investigations on specific volatile compositions of GKB-Aid 1995 fermented soymilk are pivotal to the study. The results showed that there was no any detrimental effect on fetal and skeletal development under the highest dose of GKB-Aid 1995 fermented soymilk ( $3 \mathrm{~g} / \mathrm{kg}$ body weight/day) during 20 days of the study. HS-SPME-GC-MS analysis indicated that a total of 35 identified volatile compounds were found in this new functional ingredient. In conclusion, smell of the GKB-Aid 1995 fermented soymilk, varied from the unpleasant odor of general soymilk products, has shown its possibility as a new source of functional ingredient.
\end{abstract}

Keywords: Deinococcus sp., fermented soymilk, fetal and skeletal development, volatile compounds

\section{Introduction}

Recently, the global functional food industry is striving to explore new ingredients and develop new applications to meet the demands of consumers. In 1995, a red pigment producing strain-Deinococcus sp. strain GKB-Aid 1995 was isolated from the soil in Taoyuan County of Taiwan and was found to be Gram-negative, aerobic, non-motile, and rod-shaped. Based on the bacterial identification by the $16 \mathrm{~S}$ ribosomal RNA gene sequencing and the Vitek 2 colorimetric GN card, strain GKB-Aid 1995 was identified as a member of the Deinococcus species [1]. Several studies have demonstrated that the Deinococcus species had beneficial impacts in the field of environmental science and biotechnology [2,3]; however, no information is available on their uses as functional food ingredients. As several recent studies have demonstrated that carotenoid extracts from the Deinococcus species have potential anti-oxidant and antitumor activities $[\mathbf{4 , 5}]$, this study was conducted to investigate the potential application of strain GKB-Aid 1995 as a functional food additive or ingredient.

In a culture media comprised of soymilk and yeast extract, the maximal growth rate of strain GKB-Aid 1995 from overnight was $10^{9} \mathrm{cfu} / \mathrm{ml}$ when fermented in a 20-ton bioreactor. The fermented product was shown with orange-red pigments in the nutrient broth and had a unique and strong aroma. Preliminary in vitro and in vivo studies indicated that the fermented product of strain GKB-Aid 1995 possessed potent antioxidant and anticarcinogenic effects when fermented with soymilk (unpublished data). Previous results showed that the fermented soymilk product with strain GKB-Aid 1995 was found without any genotoxic effect under the experimental conditions [1], and the no observed adverse effect level (NOAEL) of the product is greater than $10 \mathrm{~mL} / \mathrm{kg}$ body weight in a 28 day animal study in Sprague-Dawley rats (unpublished data). Although genotoxicity and systemic toxicity have been investigated, the teratogenic effects of this new ingredient on the embryo at pregnancy have not been elucidated. Therefore, the first goal of the study was focused on examining whether the fermented soymilk caused teratogenic toxicity. In the meantime, the unique odor was proposed as being a typical characteristic of fermentating the strain. Thus, the second goal of this study was to investigate the 
key odorants in the strain GKB-Aid 1995 fermented product. The results from this study may not only give further information about the product safety of fermented soymilk with strain GKB-Aid 1995 but also support its use as a potential functional food ingredient.

\section{Materials and methods}

\section{Fermentation of soymilk with GKB-Aid 1995}

One liter of broth composed of $2 \%$ sucrose, $1 \%$ peptone, $1 \%$ yeast extract, and soy milk was inoculated with an active culture of GKB-Aid 1995 and then incubated at $32^{\circ} \mathrm{C}$ for $24 \mathrm{~h}$ on a rotary shaker (120 rpm) for seed culturing prior to its scale-up production step. The scale-up of the fermentation process was performed using the same media agitated at $60 \mathrm{rpm}$ with an aeration rate of $0.5 \mathrm{vvm}$ at $32^{\circ} \mathrm{C}$ in the 20-ton fermenter for $24 \mathrm{~h}$. At the end of the cultivation, the fermented broth was heated at $60^{\circ} \mathrm{C}$, lyophilized and stored in a desiccator at room temperature. The freeze-dried powder was vigorously shaken with distilled water in order to get a final concentration of 100,200 and $300 \mathrm{mg} / \mathrm{mL}$ for a constant dosing volume of $10 \mathrm{~mL} / \mathrm{kg}$ bw /day at all dose levels to prevent the adverse effect of gavage.

\section{Animal study}

88 pregnant Sprague-Dawley rats at 8 weeks of age (BioLASCO Taiwan Co., Ltd., Ilan, Taiwan) were housed as one rat per autoclaved polyethylene cage in a controlled $12: 12 \mathrm{~h}$ light and dark schedule with free access to water and a standard diet (MFG diet; Oriental Yeast Co., Ltd, Tokyo, Japan). This study was performed in accordance with Good Laboratory Practice (GLP) and approved by the Institutional Animal Care and Use Committee (IACUC:103-9k).

\section{Prenatal developmental toxicity}

This study was conducted under the guidance of Organization for Economic Co-operation and Development (OECD) 414 (Prenatal Developmental Toxicity Study) [6]. A total of 88 rats randomly divided across 4 test groups (three dosages test groups and one negative control group) were established in the present study. The negative control group received vehicle treatment (10 $\mathrm{ml}$ distilled water), while the low-, midand high- dose groups received GKB-Aid 1995 fermented soymilk in water at doses of 1,000,2,000 and 3,000 mg/kg bw, respectively. These dose levels were selected according to the previous acute toxicity study (unpublished data) and were administered orally during the major embryonic organogenesis (Gestation days 6 to 15).

Clinical observation, body weight measurement and food intake were conducted daily during the study period. On the $20^{\text {th }}$ day of pregnancy, the rats were euthanized with inhalation of $\mathrm{CO}_{2}$, and their uterus and fetuses were delivered by caesarean sections. The number of viable fetuses, corpora lutea, implantation sites, stillbirths, resorption sites and the percentages of pre-implantation and post-implantation loss were documented. All surviving fetuses were then individually weighed, sex distributed and examined for external abnormalities. After external examination, half of the offspring in each litter were fixed with $10 \%$ neutral buffered formalin for organ examination while the remaining half were subjected to skeletal examination after $1 \% \mathrm{KOH}$ Alizarin staining.

Headspace solid-phase micro-extraction (HS-SPME) and gas chromatography-mass spectrometry (GC-MS) analyses of GKB-Aid 1995 fermented soymilk

For the analysis of volatile compounds in the GKB-Aid 1995 fermented soymilk, an Agilent 6890 gas chromatograph (Agilent Technologies, Palo Alto, CA) that is interfaced with a mass spectrometer (5973A MSD, Agilent) equipped with a fused silica capillary column $(60 \mathrm{mx} 0.25 \mathrm{~mm}, 0.25 \mathrm{~mm}$ film thickness, CP-Wax 52-CB, Chrompack, Middelburg, The Netherlands) was used. HS-SPME was used as the sampling method and was performed under optimal parameters used for highly efficient isolation of volatile compounds from fermented soymilk according to a previous study [7] with the following slight modifications. The prepared sample (50 $\mathrm{g}$ fermented liquid), after being blended with $20 \mathrm{~mL}$ of cold saline solution $(10 \%$, $\mathrm{w} / \mathrm{w})$, was added into a Schott bottle $(100 \mathrm{~mL}$, Duran, Mainz, Germany) and then placed in a water bath at $40^{\circ} \mathrm{C}$ and kept for $5 \mathrm{~min}$ for stabilization of the aliquot. Afterwards, adsorption of the volatile fraction of citrus peel using a DVB/CAR/ PDMS fiber ( $2 \mathrm{~cm}$ length, 50/30 mm film thickness, Supelco, Bellefonte, PA) was performed. Extraction was carried out for $30 \mathrm{~min}$ at $40^{\circ} \mathrm{C}$.

During headspace stabilization and extraction, the sample was agitated. After this step, the SPME fiber was removed from the bottle and placed into a GC injector heated at $220^{\circ} \mathrm{C}$ for 5 min for thermal desorption of the adsorbed compounds. Thermal desorption was carried out in the splitless mode of the injector. Separation of the desorbed compounds was achieved on the aforementioned capillary column. The column temperature program was as follows: started at $40^{\circ} \mathrm{C}$, programmed to increase to $22^{\circ} \mathrm{C}$ at $5^{\circ} \mathrm{C} / \mathrm{min}$ and held at $220^{\circ} \mathrm{C}$ for $20 \mathrm{~min}$. The helium carrier flow rate was $1.0 \mathrm{~mL} / \mathrm{min}$. GC-MS transfer line temperature was $265^{\circ} \mathrm{C}$. The MSD source and quadrupole temperatures were set to $230^{\circ} \mathrm{C}$ and $150^{\circ} \mathrm{C}$, respectively. The analyte mass spectra were compared with those from the Wiley computer library. Some of the compounds were further identified with commercially available, authentic compounds. The amount of each compound was determined based on its peak area in the total ion chromatogram.

\section{Statistical analyses}

All data were expressed as mean \pm standard deviation (SD). Mean differences between the treatment and control group were analyzed using one-way ANOVA followed by Duncan's multiple range test with SPSS version 12.0 software (IBM, Armonk, NY). The gender ratio, external, organ and skeletal examination data were analyzed by utilizing the Chi-squared 
test. A value of $p<0.05$ was used as the statistical significance criterion.

\section{Results and discussion}

Previously, the genotoxic and systemic toxicity potential of GKB-Aid 1995 fermented soymilk have been investigated [1]. As a follow-up to the previous study, the present investigation was the first to evaluate the developmental toxicity potential of GKB-Aid 1995 fermented soymilk in animals exposed daily during major organogenesis. Treatment with GKB-Aid 1995 fermented soymilk during the gestation period showed no abnormal clinical signs, miscarriages or deaths in any of the pregnant rats. Average daily body weight was not significantly different among groups (Figure 1; $p>0.05$, one-way ANOVA followed by Duncan's test). Similarly, no significant alterations in food intake were observed between control and treated groups (data not shown; $p>0.05$, one-way ANOVA followed by Duncan's test).

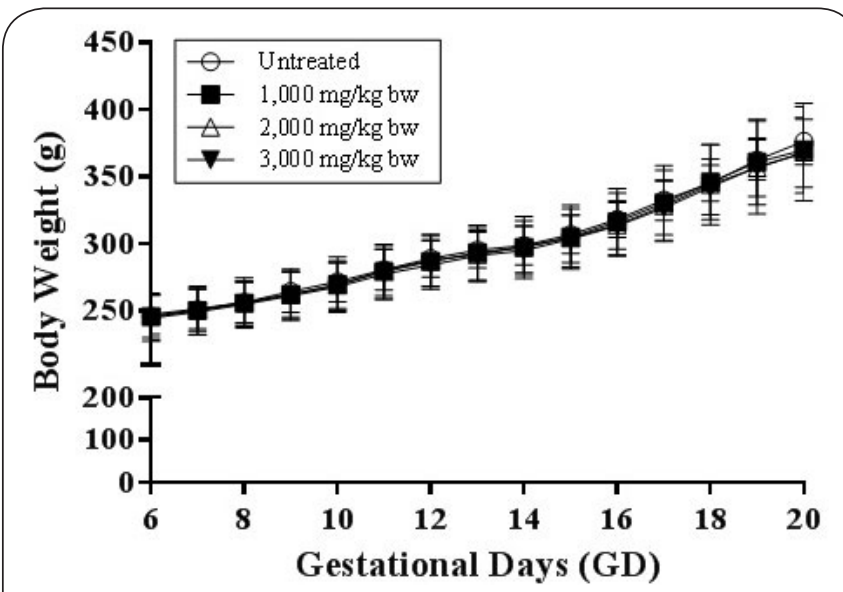

Figure 1. Changes in maternal body weights of rats exposed to the GKB-Aid 1995 fermented soymilk on gestational day 6 until parturition. Data are expressed as mean $\pm \mathrm{SD}$.

After euthanizing, the uterus and the fetuses were drawn out from the pregnant rats for evaluation. Results showed no statistically significant changes in the litter size, mean uterus weight, fetal gender ratio, corpora lutea number, number of implantation sites, live or dead fetal number, fetal resorption number, pre-implantation loss and post-implantation death (Table 1). Although there was a significant increase in the mean body weight of medium and high dose groups compared to the control group ( $p<0.05$, one-way ANOVA followed by Duncan's test), this change was not considered to be treatment-related since all values were within the normal historical range [8].

Moreover, observations and examinations carried out under a dissecting stereomicroscope on 761 treated dams and 266 control group animals showed no external and visceral abnormalities. Regarding the development of the fetal skeleton, the most frequent skeletal alterations observed were unossified
Table 1. Effects of GKB-Aid 1995 fermented soymilk on fetal development.

\begin{tabular}{|c|c|c|c|c|}
\hline & $\begin{array}{l}\text { Negative } \\
\text { control } \\
0 \mathrm{mg} / \mathrm{kg}\end{array}$ & $\begin{array}{l}\text { Low dose } \\
1000 \\
\mathrm{mg} / \mathrm{kg}\end{array}$ & $\begin{array}{l}\text { Med dose } \\
2000 \\
\mathrm{mg} / \mathrm{kg}\end{array}$ & $\begin{array}{l}\text { High dose } \\
3000 \\
\mathrm{mg} / \mathrm{kg}\end{array}$ \\
\hline Number of fetuses & 266 & 269 & 250 & 242 \\
\hline $\begin{array}{l}\text { Mean uterus } \\
\text { weight (g) }\end{array}$ & $81.8 \pm 9.4$ & $79.4 \pm 15.0$ & $80.3 \pm 26.6$ & $80.6 \pm 16.8$ \\
\hline $\begin{array}{l}\text { Mean weight of } \\
\text { fetuses }(\mathrm{g})\end{array}$ & $4.14 \pm 0.38$ & $4.18 \pm 0.41$ & $4.31 \pm 0.44^{*}$ & $4.38 \pm 0.41^{*}$ \\
\hline Fetus gender ratio ${ }^{a}$ & 0.94 & 0.95 & 0.97 & 0.89 \\
\hline $\begin{array}{l}\text { Number of } \\
\text { corpora lutea }\end{array}$ & $15.0 \pm 1.9$ & $15.6 \pm 2.3$ & $15.9 \pm 2.4$ & $15.3 \pm 3.0$ \\
\hline $\begin{array}{l}\text { Number of } \\
\text { implantation sites }\end{array}$ & $13.3 \pm 1.5$ & $13.1 \pm 2.0$ & $13.4 \pm 3.8$ & $13.0 \pm 2.6$ \\
\hline $\begin{array}{l}\text { Number of live } \\
\text { fetuses }\end{array}$ & 266 & 269 & 250 & 242 \\
\hline $\begin{array}{l}\text { Number of } \\
\text { stillbirths }\end{array}$ & 0 & 0 & 0 & 0 \\
\hline $\begin{array}{l}\text { Number of } \\
\text { resorption fetuses }\end{array}$ & 14 & 20 & 17 & 18 \\
\hline $\begin{array}{l}\text { Pre-implantation } \\
\text { loss }^{\mathrm{b}}\end{array}$ & $10.2 \pm 9.0$ & $15.5 \pm 9.6$ & $16.0 \pm 20.7$ & $14.4 \pm 12.0$ \\
\hline $\begin{array}{l}\text { Post-implantation } \\
\text { loss }^{c}\end{array}$ & $4.8 \pm 7.0$ & $7.5 \pm 9.9$ & $6.8 \pm 15.4$ & $7.4 \pm 9.7$ \\
\hline
\end{tabular}

Data are expressed as mean $\pm \mathrm{SD}$.

${ }^{a}$ Fetus gender ratio $=$ Number of male rats $\div$ number of female rats. bPre-implantation loss (\%) $=$ (number of corpora lutea-number of implantation sites $) \div$ number of corpora lutea x $100 \%$ 'Post-implantation loss $(\%)=($ number of implantation sitesnumber of live fetuses $) \div$ number of implantation sites x100 \% ${ }^{*}$ Significantly different from the negative control group $(\mathrm{p}<0.05)$.

$5^{\text {th }}$ sternebrae and unossified $2^{\text {nd }}$ or $5^{\text {th }}$ metacarpus (Figure 2). The general occurrence of unossified $5^{\text {th }}$ sternebrae was significantly lower in the mid- $(9.8 \%)$ and high-dose $(10.8 \%)$ groups compared to the control group (25.4\%) ( $p<0.05, x^{2}$-test). In addition, the rate of unossified $2^{\text {nd }}$ or $5^{\text {th }}$ metacarpus was significantly less frequent in the high-dose group (12.6\%) when compared to the control group ( $23.8 \%)\left(p<0.05, x^{2}-\right.$ test). As there was no evidence of a dose-dependent increase in fetal malformation, which suggest that GKB-Aid 1995 fermented soymilk is a safe functional food ingredient with multi-bioactivities for women during pregnancy.

Typically, fermented foods have strong and distinct flavors due to the natural biosynthesis processing from microbial interactions. In this study, a total of 35 identified volatile compounds comprising terpenes (36.17\%), pyrazines (24.82\%), ketones (13.67\%), alcohols (10.39\%) and other volatiles (14.95\%) were identified by GC-MS in GKB-Aid 1995 fermented soymilk (Figure 3). In terpenes, a significantly high proportion of limonene (33.17\%) was determined in the fermented products. It was speculated that the characteristic of limonene being insoluble in water resulted in an easier adsorption onto SPME 

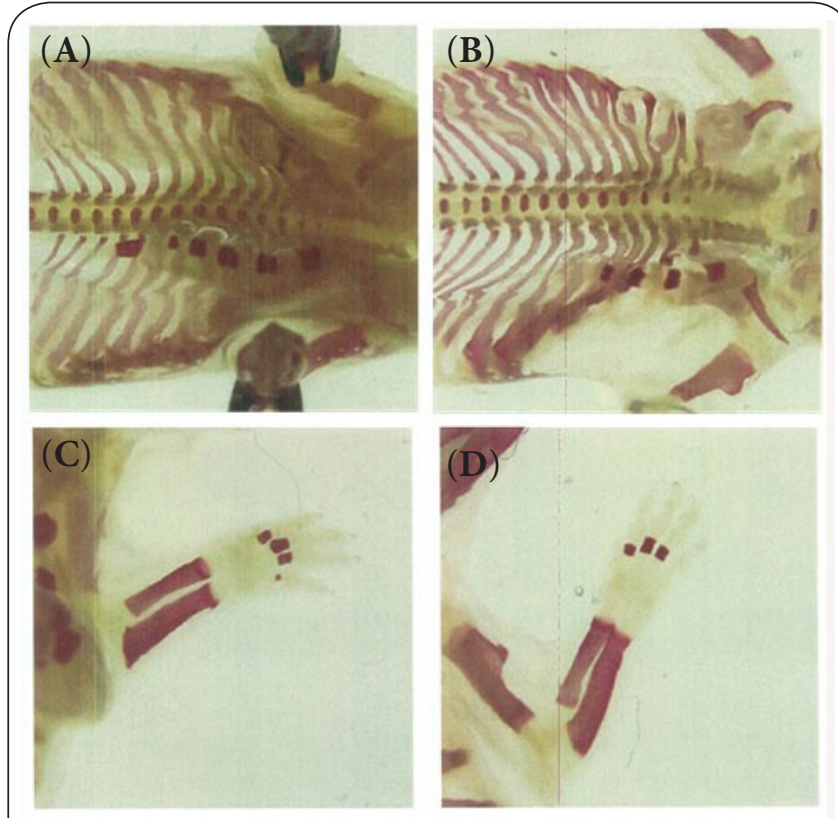

Figure 2. Representative pictures of fetal skeletal alternations from dams treated with water, or $1,000,2,000$ or $3,000 \mathrm{mg} /$ $\mathrm{kg}$ GKB-Aid 1995 fermented soymilk on days 6 to 15 during pregnancy. (A) Normal sternebrae. (B) Unossified of $5^{\text {th }}$ and 6th sternebrae. (C) Normal metacarpals. (D) Unossified $5^{\text {th }}$ metacarpus.

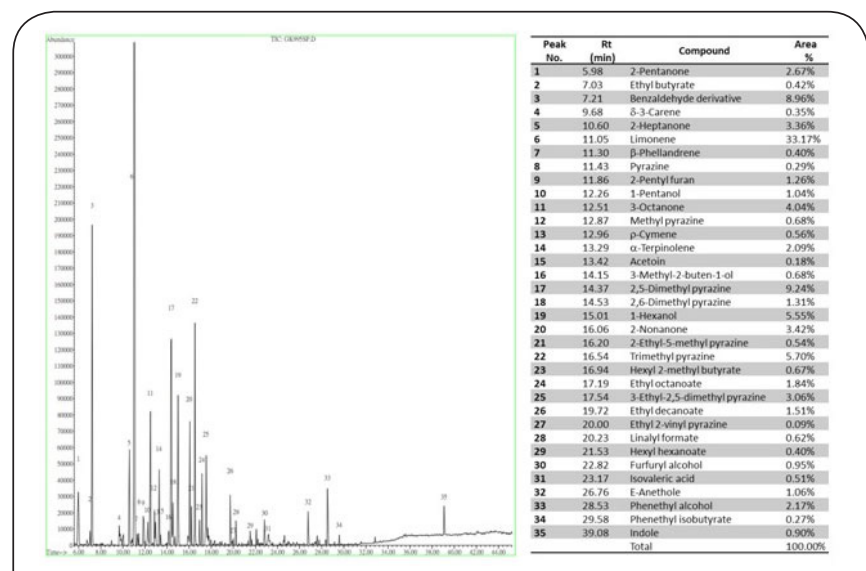

Figure 3. Total ion chromatogram of volatile components from GKB-Aid 1995 fermented soymilk by GC/MS analysis. Compounds are listed by peak number, corresponding to the table next to the figure.

fiber, especially with the addition of $\mathrm{NaCl}$ before $\mathrm{GC} / \mathrm{MS}$ analysis sampling [9]. This limonene, produced from the hydrolyzed soybean, has contributed to the pleasant lemon-like odor in the fermented products.

The pyrazines, which are heterocyclic, nitrogen containing compounds with very low sensory detection thresholds ( $\mathrm{ppb}$ to ppt levels), have drawn much attention to the product acceptance [10]. Surprisingly, a large proportion of pyrazines
(20.91\%) was identified in the products, in which the particularly high amount of 2,5-dimethyl pyrazine (9.24\%) was first to be reported in this study. The unique nutty and roasted odor characteristics of pyrazines resulted in a significantly different odor compared to traditional fermented soybean products, i.e., fermented stinky tofu, which contained sulfide compounds for more than $15 \%$ of its contents but does not have any pyrazine compounds at all [11]. The biosynthetic formation of pyrazines may be attributed to the addition of acetoin, where this addition in fermenting medium resulted in the incorporation of the acetoin substance into 2,3,5-trimethylpyrazine [12]. Furthermore, the biosynthesis of acetoin might be formed from pyruvate via a-acetolactate [13]. Therefore, it may be plausible to enhance the pyrazine biosynthesis by the addition of precursors such as acetoin in order to make such products more attractive to consumers.

The third important components of the volatile compounds in the products are ketones, especially the methyl ketones, such as 2-pentanone, 2-heptanone, 3-octanone and 2-nonanone, totaling $13.49 \%$ of the contents in the identified compounds. The formation of ketones may have resulted from alkane utilization by microorganisms [14] or from oxidation of the carboxyl end of the carbon chain of fatty acids followed by decarboxylation [15]. The olfactometric profile of ketones was compared to that of a cheese-like odor [16].

Four alcohols were also identified in the headspace of the fermented products: 1-pentanol, 3-methyl-2-buten-1ol, 1-hexanol, furfuryl alcohol and phenethyl alcohol. Most of them were detected in lower amounts in the sample, comprising $10.39 \%$ of the total contents. Phenethyl alcohol ( $2.17 \%$ of the contents) is one of the most important alcohol compounds for the flavor and fragrance industries due to its valuable rose-like odor [17]. It can be produced not only through bioconversion of L-phenylalanine but also by denovo synthesis via the shikimate pathway [17].

Lastly, the least in amount but the most in impact on odor reception were the isovelric acid and indole components. Isovaleric acid $(0.51 \%)$ was responsible for the acid-acrid odor and was recognized as a repulsive odor from most people. Similarly, indole $(0.90 \%)$ can confer a disagreeable fecal odor at an extremely low threshold value of $0.3 \mathrm{ppb}$ [18]. Indole can be produced in large quantities in both Gram-positive and Gram-negative bacteria, where indole has been identified as a signaling molecule involved in diverse functions for cell survival $[19,20]$. Even though a trace amount of isovaleric acid existed in the fermented products, its distinct unpleasant odors may affect the acceptance of the product. However, we firstly have found that a soymilk fermented with the newly identified strain presented no teratogenic toxicity as well as a unique odor resulting from the high content $(20.91 \%)$ of pyrazines.

\section{Conclusion}

There were no detrimental reproductive and developmental 
effects observed in rats attributable to GKB-Aid 1995 fermented soymilk administration. The no-observed-adverse-effect of GKB-Aid 1995 fermented soymilk is $3 \mathrm{~g} / \mathrm{kg}$ bw/day, the highest dose level administered. Thirty-five metabolites were determined and reported for the first time in soymilk fermented with a Deinococcus member. Additional research on GKB-Aid 1995 fermented soymilk, including chronic toxicity and preclinical studies, may be included in future studies to further support the safety of its consumption.

\section{Competing interests}

The authors declare that they have no competing interests.

\section{Authors' contributions}

\begin{tabular}{|l|c|c|c|c|c|}
\hline Authors' contributions & ICL & WPC & YCL & CCC1 & CCC2 \\
\hline Research concept and design & $\checkmark$ & -- & -- & -- & $\checkmark$ \\
\hline Collection and/or assembly of data & -- & $\checkmark$ & -- & -- & -- \\
\hline Data analysis and interpretation & $\checkmark$ & -- & $\checkmark$ & -- & -- \\
\hline Writing the article & $\checkmark$ & $\checkmark$ & -- & $\checkmark$ & -- \\
\hline Critical revision of the article & -- & -- & -- & $\checkmark$ & $\checkmark$ \\
\hline Final approval of article & -- & -- & -- & $\checkmark$ & $\checkmark$ \\
\hline Statistical analysis & -- & -- & $\checkmark$ & -- & -- \\
\hline
\end{tabular}

Acknowledgement

The authors thank Hsin-Yun Yang for editing the manuscript.

Publication history

Editor: James V. Rogers, Battelle Memorial Institute, USA.

Received: 07-Nov-2016 Final Revised: 16-Jan-2017

Accepted: 03-Feb-2017 Published: 13-Feb-2017

\section{References}

1. Wu SY, Li IC, Lin YC and Chen CC. Characterization and safety evaluation of a Deinococcus member as feed additive for hens. Regul Toxicol Pharmacol. 2016; 76:121-7. | Article | PubMed

2. Brim H, McFarlan SC, Fredrickson JK, Minton KW, Zhai M, Wackett LP and Daly MJ. Engineering Deinococcus radiodurans for metal remediation in radioactive mixed waste environments. Nat Biotechnol. 2000; 18:85-90. | Article | PubMed

3. Satoh K, Tu Z, Ohba H and Narumi I. Development of versatile shuttle vectors for Deinococcus grandis. Plasmid. 2009; 62:1-9. | Article | PubMed

4. Wang $\mathrm{F}$ et al. Screening of antioxidant activities of carotenoid extracts from Deinococcus. Journal of Nuclear Agricultural Sciences. 2012; 26: 900-905. | Article

5. Choi YJ, Hur JM, Lim S, Jo M, Kim DH and Choi JI. Induction of apoptosis by deinoxanthin in human cancer cells. Anticancer Res. 2014; 34:182935. | Article | PubMed

6. OECD, Test No. 414: Prenatal Development Toxicity Study. Paris: OECD Publishing. 2001.

7. Jia M, Zhang $\mathrm{QH}$ and Min DB. Optimization of Solid-Phase Microextraction Analysis for Headspace Flavor Compounds of Orange Juice. Journal of Agricultural and Food Chemistry. 1998; 46:2744-2747.

8. Derelanko MJ and Hollinger MA. Handbook of Toxicology. Second Edition. Taylor \& Francis. 2001.

9. Mirhosseini $\mathrm{H}$ et al. Solid-phase microextraction for headspace analysis of key volatile compounds in orange beverage emulsion. Food Chemistry. 2007; 105:1659-1670. | Article

10. Alpert HR, Agaku IT and Connolly GN. A study of pyrazines in cigarettes and how additives might be used to enhance tobacco addiction. Tob
Control. 2016; 25:444-50. | Article | PubMed Abstract | PubMed FullText

11. Liu Y, Miao Z, Guan W and Sun B. Analysis of organic volatile flavor compounds in fermented stinky tofu using SPME with different fiber coatings. Molecules. 2012; 17:3708-22. | Article | PubMed

12. Dickschat JS et al. Pyrazine Biosynthesis in Corynebacterium glutamicum. European Journal of Organic Chemistry. 2010; 2010:26872695. | Article

13. Chuang LF and Collins EB. Biosynthesis of diacetyl in bacteria and yeast. J Bacteriol. 1968; 95:2083-9. | Article | PubMed Abstract | PubMed FullText

14. Forney FW and Markovetz AJ. The biology of methyl ketones. J Lipid Res. 1971; 12:383-95. | Article | PubMed

15. Selke E, Rohwedder WK and Dutton HJ. Volatile components from tristearin heated in air. Journal of the American Oil Chemists Society. 1975; 52:232-235. I Article

16. Alonso L, Fontecha J and Juárez M. Development of a Headspace Gas Chromatographic-Mass Spectrometric Method for Determining Methyl-Ketones and Secondary Alcohols in Blue Cheese. Journal of Chromatographic Science. 1999; 37:108-112. | Pdf

17. Etschmann MM, Bluemke W, Sell D and Schrader J. Biotechnological production of 2-phenylethanol. Appl Microbiol Biotechnol. 2002; 59:1-8. | Article | PubMed

18. Mee Seon $Y$ et al. Comparison on Usefulness of Sampling Methods of Indoles in Airs from Swine Facility by Tenax-TA and SPME. Journal of Environmental Science International. 2013; 22:1539-1549. | Article

19. Pandey R, Swamy KV and Khetmalas MB. Indole: A novel signaling molecule and its applications. Indian Journal of Biotechnology. 2013; 12:297-310. | Article

20. Lee JH, Wood TK and Lee J. Roles of indole as an interspecies and interkingdom signaling molecule. Trends Microbiol. 2015; 23:707-18. | Article | PubMed

\section{Citation:}

Li IC, Chen W-P, Lin Y-C, Chyau C-C and Chen C-C. Teratogenicity and volatile composition evaluation of soymilk fermented with a Deinococcus member.

J Toxicol Health. 2017; 4:1.

http://dx.doi.org/10.7243/2056-3779-4-1 